\title{
Insulin secretion and impaired glucose tolerance. Reply to Mari A, Ferrannini E [letter]
}

\author{
A. B. Jenkins • L. V. Campbell
}

Received: 5 July 2010 /Accepted: 8 July 2010 /Published online: 3 August 2010

(C) Springer-Verlag 2010

Keywords Beta cell compensation - Beta cell function . Disposition index · Glucose tolerance · Insulin sensitivity Hyperglycaemia · Mathematical modelling · Pre-diabetes .

Type 2 diabetes

$\begin{array}{ll}\text { Abbreviations } \\ \beta & \text { Glucose-sensitivity of insulin secretion } \\ \text { DI } & \text { Disposition index } \\ \text { FPG } & \text { Fasting plasma glucose } \\ G & \text { Glycaemia } \\ \text { NGT } & \text { Normal glucose tolerance } \\ S & \text { Insulin sensitivity }\end{array}$

To the Editor: We welcome Mari and Ferrannini's [1] sharing of some of our views regarding the disposition index (DI) and of the utility of the basic model of Turner and co-workers [2], which we recall and apply in a different context [3]. We note the reservations regarding the DI previously expressed by Mari and Ferrannini [4, 5], but we also note the widespread and growing use of the DI, with

A. B. Jenkins $(\bowtie)$

School of Health Sciences, University of Wollongong,

Northfields Avenue,

Wollongong, NSW, Australia 2522

e-mail: ajenkins@uow.edu.au

A. B. Jenkins $\cdot$ L. V. Campbell

Garvan Institute of Medical Research,

Darlinghurst, NSW, Australia

L. V. Campbell

St Vincent's Hospital,

Darlinghurst, NSW, Australia consequences we have partly addressed. Perhaps something stronger than reservations can be justified.

We do not think that the utility of the basic model is restricted to a critique of the DI. Surely the point is not that we 'recall' a 'basic' model, but whether or not it provides an adequate description of the data, which it clearly does in one instance. We were disappointed that Mari and Ferrannini did not present any analysis of their data within the framework of the model, and instead appear to argue that the model is not relevant to the interpretation of their data. For example, they are reluctant to see their data in Fig. 1c [6] as a cloud of hyperbolae, but do not present the simple analysis which would test that interpretation. If the data did conform to the model, they seem to reject the conclusions we would draw from this as being simplistic and ignoring a wider context. We see nothing intrinsically wrong with simple conclusions if they conform to measured reality, and we do not accept the premises of the wider context as developed by Mari and Ferrannini.

Mari and Ferrannini suggest that our analysis misses the central issue of the cause-effect relationship between the glucose sensitivity of insulin secretion $(\beta)$, insulin sensitivity $(S)$ and glycaemia $(G)$, and argue that the relative constancy of fasting plasma glucose (FPG) across individuals must be the result of an inverse relationship between $\beta$ and $S$, ensuring that $G$ is relatively constant. This is both implicit in the simple model that we recall and irrelevant to a discussion of causation. We think that the key lies in Mari and Ferrannini's use here and elsewhere of the qualifier 'physiological' to describe the relationship that they, and many others, interpret in terms of a feedback loop. An evolutionary view is that our regulatory systems evolved over eons to equip us at birth with an approximate balance between the various components sufficient to take 
us to reproductive success. Thus we have evolved ranges of $\beta$ and $S$, which in combination produce a range of $G$ within which we can function sufficiently well. This range of $G$ is actually not narrow-for example, the mean and SD of the FPG data in Mari et al. (normal glucose tolerance [NGT] $5.0 \pm 0.5 \mathrm{mmol} / \mathrm{l}$ ) [6] looks impressively tight (CV 10\%), but does not directly illustrate the range of variation. More instructive is the $95 \% \mathrm{CI}(4-6 \mathrm{mmol} / \mathrm{l})$, i.e. FPG in a group of NGT individuals varied over a $40 \%$ range. We suspect that $\beta$ and $S$ are no more precisely balanced across individuals than are many other components of many other regulatory systems, and the degree of inherited or acquired imbalance between them produces the 'normal' range of $G$ seen across individuals. There may be a tendency, resulting from the necessary but subjective clinical categorisation into NGT, impaired glucose tolerance and type 2 diabetes mellitus, to forget that FPG lies on a continuum, and to downplay the range of variation in NGT individuals and the continuity of physiology across subjective divisions. Compensation driven by a feedback loop between $S$ and $\beta$ is not necessary to explain the data, and its existence cannot be inferred from data of this type.

Whether or not compensation in this or any other form exists and is involved in the pathogenesis of type 2 diabetes mellitus can only be addressed by evidence from experimental studies. We agree with Mari and Ferrannini that the work of Bergman and co-workers with the fat-fed dog model (e.g. Mittelman et al. [7]) is the strongest (though not unequivocal) experimental evidence for the existence of compensatory increases in $\beta$ in response to reduced $S$. But there is equally strong, if not stronger evidence from other models for insulin-induced insulin resistance, for reciprocal changes in $\beta$ and $S$ in response to a common stimulus, and for independent changes in $\beta$ or $S$. Any of these effects could contribute to the observed relationships between $\beta, S$ and $G$. There is no evidence that we are aware of that establishes a role for any of them in the development of human type 2 diabetes mellitus (we share Mari and Ferrannini's published views [4] of the study by Stumvoll et al. [8], which is often interpreted as support for compensatory $\beta$ in humans).
While rejecting a 'universal compensation', which they seem to relate inappropriately to our argument, Mari and Ferrannini 'prefer to stick to the simpler view that adaptation is specific of some insulin secretion parameters'. We have no evidence against this hypothesis. However, we have suggested an alternative explanation for their data, which does not include any form of compensation, and we hope that they will give it due consideration. We appreciate the analogy to Ptolemy and Copernicus, but are puzzled by its application. Compensatory $\beta$, whether universal or partial, seems to us very much a Ptolemaic epicycle, which generates needless complexity while supporting the primacy of a particular view of type 2 diabetes mellitus pathogenesis for which there is no compelling evidence. Who, we wonder, should be cast in the Vatican's role?

Duality of interest The authors declare that there is no duality of interest associated with this manuscript.

\section{References}

1. Mari A, Ferrannini E (2010) Insulin secretion and impaired glucose tolerance. Reply to Jenkins AB, Campbell LV [letter]. Diabetologia. doi:10.1007/s00125-010-1820-y

2. Matthews DR, Hosker JP, Rudenski AS, Naylor BA, Treacher DF, Turner RC (1985) Homeostasis model assessment: insulin resistance and beta-cell function from fasting plasma glucose and insulin concentrations in man. Diabetologia 28:412-419

3. Jenkins AB, Campbell LV (2010) Insulin secretion and impaired glucose tolerance. Diabetologia. doi:10.1007/s00125-010-1801-1

4. Ferrannini E, Mari A (2004) Beta cell function and its relation to insulin action in humans: a critical appraisal. Diabetologia 47:943-956

5. Mari A, Ahrén B, Pacini G (2005) Assessment of insulin secretion in relation to insulin resistance. Curr Opin Clin Nutr Metab Care 8:529-533

6. Mari A, Tura A, Natali A et al (2010) Impaired beta cell glucose sensitivity rather than inadequate compensation for insulin resistance is the dominant defect in glucose intolerance. Diabetologia 53:749-756

7. Mittelman SD, Van Citters GW, Kim SP et al (2000) Longitudinal compensation for fat-induced insulin resistance includes reduced insulin clearance and enhanced beta-cell response. Diabetes 49:2116-2125

8. Stumvoll M, Tataranni PA, Stefan N, Vozarova B, Bogardus C (2003) Glucose allostasis. Diabetes 52:903-909 